\title{
Coleccionar y narrar desde el margen
}

\section{La "zona arqueológica" de Lino Velázquez en San Dieguito Xochimancan, Texcoco.}

Nicolás Pradilla

Resumen: Lino Velázquez ha conformado una colección
de objetos que permiten pensar en formas distintas para la
articulación de valores y verdades. Con un modelo cercano al
museo, este lugar en el municipio de Texcoco, a cierta distancia
del modelo de museo comunitario y la tienda de souvenirs, toma
la responsabilidad de construir un relato propio desde el archivo.

Abstract: Lino Velázquez has shaped a collection of objects which suggest different paths for truths and forms. This place in Texcoco, México, shares with the museum some of its features, but stands in short distance from the communitarian museum and the gift shop models, Lino Velázquez takes responsibility for buit a narrative of it's own from the archive.

Palabras clave: museos, gabinetes de curiosidades, archivo, colección, identidades.

Keywords: museums, cabinets of curiosities, archive, collection, identities

El siguiente no pretende ser un documento que agote las preguntas que un espacio como la "zona arqueológica" de Lino Velázquez arroja. Constituye más un conjunto de notas y rutas para indagar en gramáticas otras de la construcción del imaginario de la cultura visual mexicana.

“¿Van a poner otro museo?"-le pregunta una niña a su padre

al pasar junto al Sagrario de Catedral en la ciudad de México.

En el lugar se encuentra un grupo de obreros cavando con picos y palas. 
La figura del museo moderno como espacio ritual de resguardo, estudio y exhibición del patrimonio es común a las urbes occidentales. Estos recintos seculares de culto a la historia como prueba fehaciente del progreso de la humanidad, de una comunidad y sus individuos, fungen como espacios de representación de sus ponderables históricos, éticos y estéticos.

El museo moderno $-y$ sus múltiples encarnaciones en el México contemporáneo- construye su narrativa y la de la sociedad en que se inserta desde la negociación con discursos hegemónicos de la cultura, la política y la pugna por la legitimación de agendas particulares en la esfera pública.

Este texto indaga en las condiciones de posibilidad de un espacio de exhibición (y enunciación) alejado de los centros oficiales de producción cultural, que plantea una lógica particular y reclama su derecho a construir archivo y relato histórico desde abajo.

A finales del siglo XIX, con la popularización de la imprenta, la litografía y la fotografía, la imagen pierde su carácter ritual y una multiplicidad de voces y sujetos van a encontrarse en la posición de producirla y generar discurso. Walter Benjamin llama la atención respecto a aquellos espacios de negociación enunciativa que se generan en los periódicos hacia finales del siglo xIX, cuando éstos comienzan a circular con mayor regularidad y se hace habitual que asignen una sección entre sus páginas para las cartas de sus lectores.' Estos espacios de réplica están animados por la forma en que la prensa se planta como un ámbito para la exposición y discusión de temas políticos, científicos, religiosos y de orden cotidiano. La operación genera un espacio de negociación entre autor y público, en el cual se cumplen funciones que son susceptibles de intercambiarse en un momento dado.

En la tesis XIII de La obra de arte en la época de su reproductibilidad técnica de 1936, Benjamin señala el interés de ciertos grupos sociales por el autoconocimiento como un reclamo de clase que a la fecha constituye un espacio de negociación que tiende a volverse cada vez más difuso. "El derecho a ser filmado" -como se titula la tesis xIII- es un reclamo ante el cual se ofrece lo que Benjamin llamó la falsificación por la vía de lo corrupto que ha llegado mediante la espectacularización de la vida cotidiana. ${ }^{2}$ El ciudadano se enfrenta

1 Walter Benjamin, La obra de arte en la época de su reproductibilidad técnica, Trad. Andrés E. Weikert, (México: Ítaca, 2003) , 75-76.

2 Benjamin, La obra de arte, 75-76. 
a su representación mediatizada, ridiculizada y reducida en televisión e Internet que se reproduce en categorizaciones sociales en imágenes y fragmentos textuales puestos en circulación desde diversos lugares. Hemos accedido al espectáculo como una comunidad imaginada $a^{3}$ que se autorepresenta mediante la caricaturización de los rasgos. La batalla está ahí: en el reflejo de una sociedad estetizada y rebasada. Producimos y archivamos muchas más imágenes de las que podemos administrar o consumir. La mediación tecnológica permite la producción acelerada y el almacenamiento de imágenes y otros datos, pero no forzosamente su comprensión. ${ }^{4}$ Ariella Azoulay nos llama la atención acerca de la tarea por asumir, como ciudadanos de la imagen, la participación en su intervención, imaginación y transmisión del archivo. ${ }^{5}$

La participación en la reconfiguración, relectura y construcción transversal del relato histórico desde el reclamo enérgico de un lugar de enunciación es señalado por Jacques Rancière como momento de lo político; ese conflicto acerca de la existencia de un escenario común y quiénes lo habitan. ${ }^{6}$ Un momento de interrupción de los efectos de la dominación: "la institución de una parte de los que no tienen parte".?

3 Tomo la categoría de comunidad imaginada de Benedict Anderson, que la describe como una comunidad limitada y soberana en donde los miembros nunca conocerán a la mayoría de los integrantes, "no los verán ni oirán siquiera hablar de ellos, pero en la mente de cada uno vive la imagen de su comunión". Benedict Anderson, Comunidades imaginadas. Reflexiones sobre el origen y la difusión del nacionalismo, Trad. Eduardo L. Suárez, (México: Fondo de Cultura Económica, 1993), 23.

4 Desde El sistema de los objetos en 1968, y en gran parte de su obra, Jean Baudrillard advertirá acerca de la forma en que el capital libera a los signos para entregarlos a su pura circulación en concordancia con la desregulación económica. Jean Baudrillard, El intercambio simbólico y la muerte (Caracas: Monte Ávila Editores, 1980), 12. En "El abismo del sentido" señala la idolatría del juego de signos y estereotipos de la secuencia espectacular de los signos por parte de "las masas". Jean Baudrillard, “El abismo del sentido”, Cultura y simulacro (Barcelona: Kairos, 1978), 117.

5 En los diversos estudios sobre fotografía que ha realizado, Ariella Azoulay ha acuñado la categoría de ciudadanía en relación con la imagen fotográfica. Apela a suspender las categorías fosilizadas que organizan a priori las relaciones entre individuos, para reconstruir las relaciones del "estar juntos" de los involucrados en el evento fotográfico. Al igual que la imagen de archivo, Azoulay utiliza la ciudadanía como "objeto de estudio y herramienta de investigación". Ariella Azoullay, "Archivo", Historia potencial y otros ensayos (México: Taller de Ediciones Económicas, 2014), 15-17.

6 Jacques Rancière, El desacuerdo. Política y filosofía (Buenos Aires: Nueva Visión, 1996), 41.

7 Rancière, El desacuerdo, 25. 
El museo occidental moderno se encuentra en una negociación constante con la representación de la comunidad que lo cobija: sus valores y creencias respecto a políticas sociales, sexuales y de identidad. ${ }^{8}$ Funge como regulador de las creencias locales respecto al arte, la historia, la ciencia y la forma en que se estructuran sus narrativas a partir de elementos normativos globales que se asumen como arquetípicos, y persiguen el ideal kantiano del proyecto ilustrado: el abandono paulatino del estado de barbarie. ${ }^{9}$

Según Carol Duncan, controlar el museo implica tener el control de la representación de la comunidad y de cómo se definen los más altos valores y verdades de la misma. ${ }^{10}$ No sabemos si el museo moderno se mantiene como un dispositivo eficaz para orientar, determinar o modelar conductas de grandes sectores de la población, pero participa de procesos simultáneos de producción de opinión pública desde una posición preponderante. ${ }^{11}$ Los museos históricos, inmersos en la espectacularización de sus colecciones, reproducen el tiempo homogéneo y vacío de la historia progresista que Benjamin advertía. ${ }^{12} \mathrm{La}$ Historia estática y monolítica que se narra desde los mausoleos del pasado heroico para dar forma y sentido al México moderno posrevolucionario que cargamos a cuestas.

La instrumentalización del museo para la educación del pueblo en los valores y verdades nacionales, que puede rastrearse en Europa desde mediados del siglo xIX, aparece también de la mano del proyecto educativo posrevolucionario en México, y tiene su momento cumbre con la inauguración del Museo Nacional de Antropología en 1964 como la consolidación de un proyecto vinculado a la tradición de la antropología social aplicada que tiene en Manuel Gamio a su ideólogo principal y a Gonzalo Aguirre Beltrán como el sucesor que continúa con el proyecto del indigenismo como institución.

Alejandro Araujo ha llamado la atención sobre cómo se han conservado prácticamente intactas las categorías sociales de identidad en los discursos antropológicos a lo largo del siglo xx, y particularmente en dos de las figuras

8 Carol Duncan, Civilizing Rituals. Inside Public Art Museums (Londres: Routledge, 1995), 2.

9 Immanuel Kant, Contestación a la pregunta: ¿Qué es la llustración? (México: Taurus, 2012), 16.

10 Duncan, Civilizing Rituals, 8.

11 Antonio Gramsci se refiere a éstos como procesos moleculares, en los cuales participan publicaciones, discusiones públicas y conversaciones que representan una voluntad colectiva hasta cierto punto homogénea. Antonio Gramsci, La política y el Estado moderno, Trad. Jordi Solé Tura, (Madrid: Diario Público. Biblioteca Pensamiento Crítico, 2009), 184.

12 Walter Benjamin, Tesis sobre la historia. Trad. Bolívar Echeverría, (México: Itaca, 2008), 51. 
más representativas y antagónicas de la discusión sobre "lo indígena": Gamio y Guillermo Bonfil Batalla. ${ }^{13}$ Estas categorías utilizadas por la sociedad para organizar y dividir jerárquicamente las situaciones y roles de sus sujetos, así como la forma en que éstos se relacionan, es la idea de la que parte Reinhart Koselleck para observar la forma en que se configura semánticamente la construcción y reproducción de conceptos contrarios, de entre los cuales llama asimétricos a aquellos desiguales y que se aplican unilateralmente. ${ }^{14}$

Los conceptos empleados para representar a los distintos actores sociales contribuyen a la configuración de su mundo. Articulan la identidad y su relación con los demás. Como señala Araujo, éstas pueden producir relaciones de subordinación o dependencia. Las relaciones de subordinación son aquellas relaciones desiguales donde existe un grupo que ejerce poder sobre otro. Koselleck nos dice que la mayoría de las veces, el campo histórico se trabaja con "conceptos asimétricos y desigualmente contrarios". ${ }^{15}$ Así, la serie de pares que designan el devenir mexicano y de gran parte de América Latina parece estar estructurada desde las categorías sociales de identidad "conquistador" / "conquistado" o "blanco" / "indio", que, como describe Araujo en "Mestizos, indios y extranjeros..." permanecen ocultos, no dichos cada vez que "lo indio" se utiliza como una categoría de identidad que se produce desde un otro que lo nombra como tal. ${ }^{16}$

El relato oficial de la historia de nuestro país está marcado por el indigenismo de Estado que se forja a partir del pensamiento de Gamio. El indigenismo como saber participa del sesgo clasificatorio que conforma políticas de dominación que se ejercen desde distintas formas culturales predominantes dentro de la sociedad civil, ${ }^{17}$ y destila sobre los aparatos de reproducción cultural que articulan el relato histórico nacional, donde los museos tienen un lugar fundamental.

13 Alejandro Araujo, “Mestizos, indios y extranjeros: lo propio y lo ajeno en la definición antropológica de la nación. Manuel Gamio y Guillermo Bonfil Batalla", Nación y alteridad. Mestizos, indígenas y extranjeros en el proceso de formación nacional, Coord. Daniela Gleizer y Paula López Caballero, (México: UAM-Cuajimalpa, 2015), 197-242.

14 Reinhart Koselleck, "Sobre la semántica histórico-política de los conceptos contrarios asimétricos" Futuro pasado. Para una semántica de los tiempos históricos, (Barcelona: Paidós, 1993).

15 Koselleck, "Sobre la semántica histórico-política de los conceptos contrarios asimétricos", 207.

16 Araujo, "Mestizos, indios y extranjeros".

17 Las formas culturales predominantes junto con aquellas ideas de mayor influencia en una sociedad constituyen la supremacía cultural que Gramsci llama hegemonía, y que Edward Said considera un concepto indispensable para comprender cómo un discurso como el orientalismo 
Edward Said llama orientalismo a "la distribución de una cierta conciencia geopolítica en unos textos estéticos, eruditos, económicos, sociológicos, históricos y filológicos." El orientalismo es una distinción geográfica que se vacía en una serie de intereses que lo reproducen desde la intención de comprenderlo -y en ocasiones controlarlo- como esa otra mitad. ${ }^{18}$

Araujo considera que la operación implícita en la construcción del campo antropológico mexicano toma lo indígena como "territorio orientalizado" equiparable al principio de categorización señalado por Said, que delimita a Oriente desde Europa y reitera esta separación al nombrarla constantemente desde la exterioridad. ${ }^{19}$ En México, esta exterioridad está marcada desde las categorías racializadas de "mestizo" / "indio", que tienen variantes y particularidades regionales en el "güero" / "moreno", "rico" / "pobre" como componentes de esta incomprensión y exotización que construyen "territorios orientalizados"y territorios completamente invisibilizados dentro de una misma comunidad imaginada que en realidad se configura de fragmentos en pugna identitaria.

Para Koselleck, nombrar y estudiar las categorías identitarias produce de manera cotidiana la separación; éstas producen el mundo social y lo reiteran en el momento de su aparición.

II

Hasta aquí, he tratado de señalar una serie de problemáticas desde las cuales me interesa abordar el caso de un pequeño espacio de exhibición que tiene características coincidentes con el museo y con espacios de venta de artesanías, pero cuyo nicho descriptivo más adecuado sea, posiblemente, el de los gabinetes de curiosidades..$^{20}$ El espacio de exhibición al cual me refiero,

perdura y se reproduce como campo de estudio académico y par antagónico para la visión de occidente, que lo produce política e ideológicamente. Edward W. Said, Orientalismo (Barcelona: Random House Mondadori, 2002), 26-27.

18 Said, Orientalismo, 34-35.

19 Araujo, "Mestizos, indios y extranjeros", 11-12.

20 El proyecto al que me refiero puede ser considerado un archivo o una colección, sin embargo el carácter intuitivo alejado de la taxonomía linneana y los derroteros positivistas le coloca en una posición más cercana al Wunderkammer, cuya lógica se aleja del museo y la tienda de artesanías. 
fue abierto al público hace cinco años por Lino Velázquez, un habitante de San Dieguito Xochimancan, en el municipio de Texcoco, Estado de México.

Don Lino, como lo conocen sus vecinos, ha conformado una colección creciente de objetos que reúne bajo el término arqueología. La señal a la orilla de la carretera que alerta sobre la ubicación del espacio de exhibición, apunta con una flecha: "Zona arqueológica en miniatura". El letrero está decorado con el dibujo esquemático de una pirámide emulando los señalamientos oficiales.

Podríamos sucumbir ante la tentación de catalogar el lugar de Lino Velázquez como un museo comunitario. Desde hace más de treinta años, algunas de las comunidades mexicanas excluidas de la administración del relato históricoidentitario crean y organizan espacios con la estructura de pequeños museos comunitarios. Estos espacios coadyuvan en la articulación de los relatos locales desde procesos de gestión iniciados en la propia comunidad. Esta es una de las diferencias notables con los museos municipales o estatales. Si bien, antropólogos e investigadores relacionados con el Instituto Nacional de Antropología e Historia (INAH) han participado en capacitación, financiamiento y seguimiento, éstos museos suelen partir del interés de un grupo de individuos al interior de la comunidad, y permiten generar narrativas de autoarticulación histórica que en muchos casos discuten con los relatos oficiales que tienden a la normalización.

Manuel Burón Díaz asegura que son dos los principales motivos por los cuales ciertas comunidades deciden conformar sus propios museos: por un lado, como reacción a la falta de condiciones para conservar piezas arqueológicas y/o de carácter patrimonial encontradas en la zona. Por otra parte, los museos comunitarios permiten articular la historia de la comunidad y sus habitantes en un discurso propio. ${ }^{21}$ El común denominador es que estos son gestionados por la misma comunidad, o por particulares que se dedican a esta tarea sin perseguir el lucro. Sin embargo, también advierte que estos centros no nacen exclusivamente de la necesidad de explicitar sus identidades, sino que su creación obedece también a dinámicas económicas y culturales que tienen -en la noción de museo construida desde las instituciones del Estado- un modelo imitable de atracción turística y de aprovechamiento de oportunidades ofrecidas por las políticas culturales que el mismo Estado desarrolla.

El museo comunitario como espacio creado para la recuperación de memoria colectiva se encuentra en constante negociación con el dominio historiográfico y el centralismo de los museos tradicionales, pero también con la utilización de las herramientas museológicas con las cuales presumiblemente se ejerce esta

21 Manuel Burón Díaz, "Los museos comunitarios mexicanos en el proceso de renovación museológica", Revista de Indias núm. 254, vol. LXXII (2012): 178. 
dominación. Las comunidades que han decidido instalar museos comunitarios se colocan en una posición de legitimación frente al Estado al pasar de ser exhibidos desde el discurso de la antropología social sostenida desde diversas instituciones estatales, a exhibirse bajo herramientas traducidas a los intereses de la comunidad.

III

La "zona arqueológica" de Lino Velázquez se encuentra en San Dieguito Xochimancan, población que junto con San Nicolás Tlaminca, es una de las dos únicas vías de acceso a la zona arqueológica del Tezcotzingo (pequeño Tezcuco en náhuatl) en Texcoco, Estado de México. El cerro del Tezcotzingo alberga los restos de lo que se cree fueron los jardines del Tlatoani Acolhua Nezahualcóyotl (1402-1472). Es considerado el primer jardín botánico del mundo, y según narraciones de Fernando de Alva Ixtlilxochitl, ahí se cultivaban plantas medicinales y se criaban animales exóticos. En el sitio aún se conservan piletas talladas directamente en la roca y rastros de acequias que bañaban las terrazas con agua transportada desde la Sierra Nevada mediante un acueducto. ${ }^{22}$ Actualmente, la zona arqueológica carece de un museo de sitio y es evidente el descuido por parte de autoridades estatales y del INAH. La señalización, limpieza y vigilancia son insuficientes y, en ocasiones, los pobladores de San Dieguito son quienes se hacen cargo.

San Dieguito Xochimancan cuenta con alrededor de 5,000 habitantes. Las actividades económicas preponderantes combinan servicios, producción de flor de invernadero y tareas agrícolas de autoconsumo que se llevan a cabo en predios colindantes con el Tezcotzingo.

Algunos kilómetros al sur, dentro del mismo municipio de Texcoco, se ubica San Miguel Coatlinchan, de donde fue extraído en 1964 el monolito de basalto de 167 toneladas conocido como Tláloc, que desde aquel año recibe a los visitantes del Museo de Nacional de Antropología en la ciudad de México. ${ }^{23}$

22 Fernando de Alva Ixtlilxochitl, "Historia de la nación chichimeca", Biblioteca Virtual Antorcha (sitio web), consultado el 15 de mayo de 2015, http://www.antorcha.net/biblioteca virtual/ historia/chichimeca/indice.html

23 Sandra Rozental ha trabajado el caso del traslado del monolito a la ciudad de México a profundidad. Ver Sandra Rozental y Jesse Lerner, La piedra ausente (México y Estados Unidos: Foprocine/ INAH, 2013). También Sandra Rozental, "La creación del patrimonio en Coatlinchan: ausencia de piedra, presencia de Tláloc", La idea de nuestro patrimonio histórico y cultural, Coord. Pablo Escalante Gonzalbo, (México: Dirección General de Publicaciones/ Conaculta, 2011), 341-360. 
Hacia el oeste, en los límites del poblado con Santa María Nativitas, se encuentra una mina de la cual se extraen arena y pumita, conocida popularmente como piedra pómez. Es precisamente la pumita el material más utilizado por Lino Velázquez para realizar las tallas que encontramos en la "zona arqueológica" que ha abierto en su casa.

\section{CLASIFICAR}

En "The Museum's Furnace", Eugenio Donato sitúa la labor de los personajes de Gustave Flaubert, Bouvard y Pécuchet, en un lugar más cercano al museo que a la biblioteca. Son la arqueología, la geología y la historia los universos que detonan preguntas en relación con el origen, causalidad, representación y simbolización. Según Donato, es a través de la arqueología que los personajes de Bouvard y Pécuchet buscan artefactos "originales" que develen el sentido de "una historia subsiguiente más amplia".24

La organización y clasificación más o menos rigurosa de los restos materiales es un modelo privilegiado en Occidente para el estudio de los individuos y su entorno desde el Renacimiento, que tiene en la colección enciclopédica de objetos un lugar para el desarrollo y puesta en circulación de formas discursivas de la historia, biología, antropología o historia del arte como disciplinas del conocimiento. El gabinete de curiosidades como teatro del mundo y de la memoria, espacio de resguardo, contemplación y tribuna de ostentación de poder y cultura para la aristocracia europea del siglo xvı, será un antecedente directo de los museos y las colecciones occidentales que aparecen como tales durante el siglo xIx.

En Las palabras y las cosas, Michel Foucault señala cómo es que los jardines botánicos y gabinetes de historia natural, van a modificar la forma de conocer

24 Donato se refiere a Bouvard y Pécuchet, novela póstuma de Flaubert que narra el ejercicio infructuoso de dos personajes que deciden abandonar su tarea monótona como copistas burócratas para lanzarse a explorar una gran cantidad de actividades que invariablemente resultan infructuosas. Bouvard y Pécuchet exploran la agricultura, la química, la geología, la medicina, la pedagogía o la historia hasta resolver que lo mejor es volver a la tarea sistemática de copiar. Copiar absolutamente todo lo que tengan en frente y crear taxonomías. Gustave Flaubert, Bouvard y Pécuchet (México:Tusquets, 1999); Eugenio Donato, “The Museum's Furnace: Notes Toward a Contextual Reading of Bouvard and Pécuchet" en Textual Strategies: Perspectives in Post-Structuralist Criticism, Ed. Josué V. Harari, (Ithaca: Cornell University Press, 1979), 214. citado en Douglas Crimp, "Sobre las ruinas del museo" en Hal Foster (Ed.), La posmodernidad, (Barcelona: Kairos, 1985), 83. 
a animales y plantas. ${ }^{25}$ No es el deseo de saber lo que se modifica con la instauración de estos modos de exponer, sino la manera en que se ve y cómo se describe; la mirada y el discurso; ${ }^{26}$ la historia natural como denominación de lo visible. Esta catalogación reticulada basada en la pertenencia común de las $\operatorname{cosa}^{27}$ determinará en gran medida la idea de organización del mundo para su estudio a partir del siglo xvill. La idea de archivo y de colección, un nuevo esquema de organización para las bibliotecas, catálogos e inventarios como espacios de producción de conocimiento, conformarán una nueva manera de hacer la historia, que tendrá en los gabinetes de historia natural y de curiosidades de los siglos xvı y Xvil, el modelo que, junto a la clasificación taxonómica linneana, permitirán durante el siglo xix la escritura de lo que Foucault llama "una historia finalmente 'verdadera'".28

En 1947, André Malraux comenzará a reunir un archivo de imágenes con el cual conforma su musée imaginaire, un modelo al cual se ha vuelto en los últimos años para pensar en la circulación y archivo de imágenes en Internet. El museo sin muros que Malraux propone, consiste en el montaje de reproducciones fotográficas de obras de arte de todo el mundo, desde la época clásica hasta la pintura impresionista. Malraux dispone las imágenes de su musée imaginaire en pares sobre soportes de papel de medidas homogéneas que recuerdan a la doble página de un libro abierto. El museo de Malraux no pretende ser el museo definitivo que concentre todas las obras de arte de la humanidad; es una propuesta abierta que invita a que cada quien conforme su propio musée imaginaire con aquello que considere valioso. ${ }^{29} \mathrm{El}$ lector en la posición permanente de convertirse en quien escribe la historia, el momento en que "el trabajo mismo toma la palabra." ${ }^{30}$

25 El gabinete de historia natural y el gabinete de curiosidades o Wunderkammer tienen fronteras difusas. Estas reproducciones a escala del mundo circundante suelen apreciar el exotismo de la colección, en la cual se reúnen objetos de la historia natural, lo monstruoso y lo extraño, rocas, pintura u objetos de carácter religioso. Esta forma de conocimiento comienza a cobrar interés en Europa occidental durante el siglo xvı, cuando también se comienzan a organizar los primeros jardines botánicos.

26 Michel Foucault, Las palabras y las cosas: una arqueología de las ciencias humanas, Trad. Elsa Cecilia Frost, (México: Siglo XXI, 2010), 147.

27 Foucault, Las palabras y las cosas, 148.

28 Foucault, Las palabras y las cosas, 147.

29 Derek Allan, "André Malraux, the Art Museum and the Digital Musée imaginaire", Malraux, Literature and Art. (Sitio Web), consultado el 15 de mayo de 2015. http://home.netspeed.com. au/derek.allan/musee\%20imaginaire.htm.

30 Walter Benjamin, La obra de arte..., 75-76. 
En 2003, Lino Velázquez, construye con cemento un circuito miniatura para automóviles de juguete con el propósito de que su hijo más pequeño juegue en el patio de la casa familiar. Años más tarde el pequeño fallece y el lamentable suceso llevará a su padre a iniciar una tarea que bien puede considerarse como la puesta en marcha de la ampliación de un archivo que ya llevaba años conformando a partir de recortes de revistas, fotografías y algunos libros en donde los temas principales son el patrimonio arquitectónico y las culturas prehispánicas. Lino toma el circuito miniatura como estructura de organización, y comienza a edificar reproducciones de algunos sitios arqueológicos alrededor del mundo con la ayuda de cemento y pumita, piedra que consigue en la mina con la que colinda su terreno. Hacia el año 2010, que es cuando comienza a producir estos proyectos arquitectónicos en miniatura, don Lino ya cuenta con un archivo considerable de recortes de revistas, postales y volantes, así como algunos libros de arqueología mexicana, que utiliza como modelos para fabricar las piezas en tres dimensiones.

La labor constante de Lino Velázquez recuerda la tarea de Bouvard y Pécuchet, los personajes copistas de Flaubert que utilizan la biblioteca como fuente para llevar a cabo innumerables proyectos que dan paso a otros nuevos tras concluida la faena anterior sin demasiado éxito. Lo suyo es una labor de archivo en donde la reproducción del mismo archivo permite generar otros archivables. La producción no está filtrada por la aparente legitimidad de las fuentes; es una construcción personal de lo que es la historia y la trascendencia lo que parece regir el principio de selección, sin importar que aquello a reproducir se trate de la fotografía de una hacienda yucateca publicada en TVNotas debido a que se utilizó como locación para La dueña. Es la trascendencia, que Lino Velázquez corrobora mediante la reproducción mediática, lo que le asigna importancia al objeto. Es a través de la espectacularización en telenovelas, revistas, postales o libros monográficos, que don Lino desentierra el material de archivo.

La práctica y el lugar que albergan su trabajo sistemático se encuentran más cerca del gabinete de curiosidades que del museo o la tienda de artesanías que aprovecha la colindancia con la zona arqueológica de Tezcotzingo. Su "zona arqueológica" tiene más de excavación transversal en el lenguaje, que de espacio para la articulación del relato identitario o tienda de souvenirs. 
LOS OBJETOS

Al llegar a la "zona arqueológica" uno encuentra el circuito miniatura para autos de juguete: ahí, en primer termino, podemos observar una reproducción del Tezcotzingo conectado al Caño Quebrado en miniatura, que es el acueducto que llevaba agua desde la Sierra Nevada a los jardines de Nezahualcóyotl; el acueducto del Padre Tembleque, recientemente catalogado como Patrimonio de la Humanidad por la Unesco, que según consta una inscripción sobre el cemento, fue edificado en 1543; y el acueducto de los Remedios, también en el Estado de México. Todo esto en una cadena que cruza sobre el circuito para autos de cuatro carriles. Más adelante encontramos la pirámide de Micerino en Guiza, Egipto; el Templo Mayor convive con la antigua Basílica de Guadalupe, el templo de Kukulcán en Chichén Itzá y el santuario del Señor de Chalma.

Muchas de las reproducciones tienen varias versiones. Lino explica que repite las construcciones o tallas por considerar que es necesario ajustar elementos arquitectónicos y otros detalles formales, o utilizar materiales y técnicas más ligeros, que le permitan transportarlos con facilidad. Con este propósito, ha hecho más de una versión de piezas que corresponden al Templo Mayor de Tenochtitlan o a la Calzada de los Muertos de Teotihuacan.

Además de la gran cantidad de réplicas miniatura de pirámides de distintas culturas prehispánicas, se pueden encontrar tallas de distintos tamaños del Tláloc de Coatlinchan y distintos cascos de hacienda que, al ser locaciones recurrentes en telenovelas nacionales, aparecen con frecuencia en televisión y publicaciones como TVNotas o TVyNovelas, así como en propaganda turística de los gobiernos estatales.

La colección de la"zona arqueológica" de Lino Velázquez crece continuamente y se enfrenta a un problema evidente de espacio. Si bien, todo lo que se puede ver y levantar del suelo está a la venta, lo que parece animar su construcción es, como en Bouvard y Pécuchet, el estímulo intelectual más que la comercialización. Los fines de semana suele subir a la zona arqueológica de Tezcotzingo para ofrecer visitas guiadas y vender algunas de las piezas pequeñas de la colección.

La casa que alberga la "zona arqueológica", aloja piezas en cada rincón: en la azotea, desde donde se observa la mina contigua, encontramos otra reproducción del Templo Mayor, varios Tláloc y Quetzalcóatl de distintos tamaños, así como reproducciones de pirámides mayas entre las que se reconocen construcciones de Palenque y Tikal; un curioso conjunto de piedras redondas pintadas en amarillo y ocre inspiradas en la serie animada Dragon Ball $Z$, e incluso un trozo de pumita tallado que reproduce el cartel de la célebre película de Hollywood, Ben-Hur. 
En la estancia, al interior de la casa, se encuentra una parte importante del archivo: fotografías, postales, recortes de revista y algunos libros. También hay altares en donde se mezclan piezas de barro cocido confeccionadas por don Lino, reproducciones industriales de pintura flamenca y antiguos calendarios de pared. El muro principal de la habitación tiene una pintura mural que representa la piedra del sol mexica y a sus pies, varias tallas recientes en pumita basadas en piezas olmecas y mexicas.

ITERACIONES DE UN ARCHIVO

El archivo de don Lino se produce a sí mismo a partir de recortes de imágenes impresas en postales, revistas o libros de arqueología, en un sentido performático. Las reproducciones tridimensionales de las fotografías en revistas, postales y libros, parecen ser espejos nutridos por un ejercicio de reconocimiento formal de la trascendencia del imaginario visual nacional. Lo de Lino Velázquez tiene el carácter de un taller abierto en donde se llevan a cabo ejercicios de aprehensión formal en ciclos donde no hay originales. El archivo se mueve; los elementos de la "zona arqueológica" no tienen un lugar fijo; son las relaciones formales entre objetos dispares lo que rige las relaciones espaciales. La copia de la copia de la copia. Cada objeto, ya sean recortes de papel, calendarios o pequeñas esculturas, es un detonador potencial de la construcción de otro. Las réplicas esculpidas en piedra pómez arrojan nuevas preguntas: una vez terminadas, se convierten en bocetos para una nueva versión. Es la producción del signo; la filiación a un orden de la trascendencia de lo visual identitario, a través de la secuencia espectacular del juego de los signos. ${ }^{31}$

El origen del archivo está vinculado con el juego y la curiosidad. Si el circuito miniatura para autos de juguete es el primer proyecto constructivo, también es lo que proporciona unidad al conjunto central. El proceso de talla y la fabricación de otros objetos tiene un carácter temporal que recuerda a maquetas constructivas previas a una obra arquitectónica. Un proceso de reconocimiento permanente que se utiliza para generar otro proceso de reconocimiento nuevo. Sobre el uso recurrente del juego en la práctica de Francis Alÿs, Michael Taussig

31 La resistencia de "las masas" al "imperativo de la comunicación racional" que Baudrillard considera parte de la exigencia de espectáculo, produce aquí un laboratorio formal desde el archivo. Jean Baudrillard, “El abismo del sentido”, Cultura y simulacro. (Barcelona: Kairos, 1978), 117. 
se pregunta si más que indagar en el juego infantil, el acto de invocar la historia no es cavar en su pérdida mundial. ${ }^{32}$

\section{RECUPERACIÓN}

La tarea a la que don Lino se ha dedicado desde 2010, tiene también un sentido de recuperación y cavado transversal en el imaginario visual mexicano a partir de fuentes que a primera vista resultan insólitas; de ídolos y patrimonio recuperados de entre la piedra de una mina de extracción industrial, de revistas de espectáculos, postales turísticas y la memoria de la pérdida personal. La historia, que en el caso del proyecto de Lino Velázquez no sugiere una linealidad homogénea, parece cambiar con cada nuevo indicio e inserción mediante la producción de elementos de la colección.

Si bien, la idea del valor está dada a partir de una negociación con los discursos hegemónicos sobre patrimonio y obra artística común a instituciones y colecciones occidentales, el relato que construye don Lino tiende hacia una gramática distinta que funde el tiempo en territorio, en comunidad imaginada y espacio de rito secular a través de los objetos como portadores de saberes en sí mismos.

Los distintos objetos coexisten sin que parezca importar demasiado si corresponden temporal o geográficamente. La escala de cada uno tampoco es un problema. Lo importante parece ser la sensación general, el orden al que pertenecen. La manera en que se articula toda la puesta en escena como signo. La percepción del todo como una fuente para indagar en la historia y la visualidad de lo nacional desde derroteros propios, la intervención, imaginación y transmisión del archivo desde el reclamo de un lugar de enunciación.

V

El proyecto museal de Lino Velázquez se aleja de las tipologías más comunes encontradas en museos comunitarios. A pesar de ser un espacio abierto al público, no muestra objetos que podrían ser considerados patrimoniales y tampoco pretende articular un relato identitario de la comunidad. Lo que se exhibe en la "zona arqueológica" puede entenderse como la producción contemporánea de un archivo que explora valores y verdades desde el ejercicio

32 Taussig se refiere a REEL-UNREEL (2011), filme comisionado por la dOCUMENTA (13) y realizado con niños de Kabul, Michael Taussig, "Política, juego y arte. La documentación de "Afganistán", Francis Alÿs: Relato de una negociación, (México: INBA, 2015), 205. 
formal y la reproducción. Esta producción se articula alejada de la lógica de mercado o la intención de construcción historiográfíca. Es un espejo peculiar de la reproducción de la identidad visual de lo mexicano espectacular desde el margen.

La libertad como aquella cualidad de los que no tienen ninguna otra, ${ }^{33}$ abre la posibilidad de conformar este espacio de enunciación. El proyecto de Lino Velázquez se puede entender como un espacio de construcción de lo común, un espacio de lo político en el cual se toma el derecho a la articulación del relato propio, donde el trabajo mismo toma la palabra en la construcción de un territorio de lo común, que contribuye a contrarrestar los procesos de exclusión y orientalización; a la construcción de opinión pública desde el margen y desde otros modelos e identidades.

Es a través de los procesos de diferenciación que se definen los discursos hegemónicos que forman parte de la construcción de identidad. La posibilidad de establecer "museos" otros, permite generar un espacio de construcción de relato histórico e identitario que negocia permanentemente con aquellos enunciados desde instituciones públicas y privadas. La producción de la zona arqueológica de Lino Velázquez está mediada por la circulación de signos desde el centro, pero es el diálogo con éstos desde una posición excéntrica lo que permite la producción de un relato particular que establece los cimientos de otra comunidad imaginada. 


\section{BIBLIOGRAFÍA}

Anderson, Benedict, Comunidades imaginadas. Reflexiones sobre el origen y la difusión del nacionalismo, Trad. Eduardo L. Suárez, (México: Fondo de Cultura Económica, 1993).

Araujo, Alejandro, "Mestizos, indios y extranjeros: lo propio y lo ajeno en la definición antropológica de la nación. Manuel Gamio y Guillermo Bonfil Batalla", Nación y alteridad. Mestizos, indígenas y extranjeros en el proceso de formación nacional, Coord. Daniela Gleizer y Paula López Caballero, (México: UAM-Cuajimalpa, 2015).

Azoullay, Ariella, "Archivo", Historia potencial y otros ensayos (México: Taller de Ediciones Económicas, 2014).

BAUdrILlaRD, Jean, El intercambio simbólico y la muerte (Caracas: Monte Ávila Editores, 1980)

1978).

Benjamin, Walter, La obra de arte en la época de su reproductibilidad técnica, Trad. Andrés E. Weikert, (México: Itaca, 2003).

2008).

CRIMP, Douglas "Sobre las ruinas del museo" en Hal Foster (Ed.), La posmodernidad, (Barcelona: Kairos, 1985).

Duncan, Carol, Civilizing Rituals. Inside Public Art Museums (Londres: Routledge, 1995).

Flaubert, Gustave, Bouvard y Pécuchet (México: Tusquets, 1999).

Foucault, Michel, Las palabras y las cosas: una arqueología de las ciencias humanas, Trad. Elsa Cecilia Frost, (México: Siglo XXI, 2010).

Gramscl, Antonio, La política y el Estado moderno, Trad. Jordi Solé Tura, (Madrid: Diario Público. Biblioteca Pensamiento Crítico, 2009).

Kant, Immanuel, Contestación a la pregunta: ¿Qué es la llustración? (México: Taurus, 2012).

Koselleck, Reinhart, "Sobre la semántica histórico-política de los conceptos contrarios asimétricos" Futuro pasado. Para una semántica de los tiempos históricos, (Barcelona: Paidós, 1993).

MedinA, Cuauhtémoc et al., Francis Alÿs: Relato de una negociación, (México: INBA, 2015). 
Rancière, Jacques, El desacuerdo. Política y filosofía (Buenos Aires: Nueva Visión, 1996).

RozentAL, Sandra, "La creación del patrimonio en Coatlinchan: ausencia de piedra, presencia de Tláloc", La idea de nuestro patrimonio histórico y cultural, Coord. Pablo Escalante Gonzalbo, (México: Dirección General de Publicaciones/ Conaculta, 2011).

SAID, Edward W., Orientalismo (Barcelona: Random House Mondadori, 2002).

\section{REVISTAS}

Burón Díaz, Manuel, "Los museos comunitarios mexicanos en el proceso de renovación museológica", Revista de Indias núm. 254, vol. LXXII (2012).

WEB

AlLAN, Derek, "André Malraux, the Art Museum and the Digital Musée imaginaire", Malraux, Literature and Art. (Sitio Web), consultado el 15 de mayo de 2015. http://home.netspeed.com.au/derek.allan/musee\%20imaginaire.htm.

DE Alva Ixtlilxochitl, Fernando, "Historia de la nación chichimeca", Biblioteca Virtual Antorcha (sitio web), consultado el 15 de mayo de 2015, http://www. antorcha.net/biblioteca_virtual/historia/chichimeca/indice.html.

DVD

RozentAL, Sandra y Lerner, Jesse, La piedra ausente (México y Estados Unidos: Foprocine/ INAH, 2013). 
